\title{
An Aggregation Function Based on Pairwise Comparisons
}

\author{
Joël N. Kapiamba \\ Faculty of Sciences \\ University of Kinshasa \\ Kinshasa, DR Congo \\ Berthold Ulungu E.-L. \\ Faculty of Mechanics \\ Kinshasa, DR Congo
}

Institut Supérieur des Techniques Appliquées

\author{
Ruffin-Benoît M. Ngoie \\ Department of Mathematics \\ Institut Supérieur Pédagogique \\ Mbanza-Ngungu, DR Congo \\ Pascal K. Mubenga \\ Faculty of Sciences \\ University of Kinshasa \\ Kinshasa, DR Congo
}

\begin{abstract}
Multiple-Criteria Decision Aid (MCDA) has long been considered in a single decision-making framework. Nowadays, the need to take into account several contradictory opinions handled by several decision-makers arises. Thus, researchers are interested in multi-criteria problems involving several decisionmakers. In this context, to solve the classification problem, we propose an aggregation model based on the geometric mean and the comparison score on the considered criteria. Comparisons with two methods, AHP and TOPSIS, are performed on numerical data. It is clear that the proposed aggregation function is better depending on the complexity of the calculation and the computation time. Further research in this field is proposed.
\end{abstract}

Keywords: Aggregation Function, Group Decision, Multi-Criteria Decision Aiding, Ranking Problem.

\section{INTRODUCTION}

It is always difficult and complex to decide with consistency when an objective set is given. Decisionmakers are often faced with decision-making situations in which several points of view (objectives or criteria) must be considered simultaneously [1]. Decision-making is the study of identifying and choosing alternatives to find the best solution based on different factors while considering decisionmakers' expectations [2].

Also, as noted [2], any decision is made in an environment, which is defined as a collection of information, alternatives, values and preferences available at the time the decision is to be made. The most difficult point in decision-making is the multiplicity of used criteria to judge alternatives. These objectives are often conflicting and, in most cases, different groups of decision-makers are involved in the process.

Indeed, decision-making goes beyond the framework of the mono-decision-maker [3]. The current trend is for a group of people concerned by the expertise on the decision. The different perspectives of the decision-makers (DM) must be taken into account in order to arrive at a consensual decision. The choice between alternatives is reached by a process that aims to aggregate individual preferences into a collective preference. According to [4], aggregation functions are usually defined and used to combine and summarize several numerical values into one, so that the final result of the aggregation takes into account, in a prescribed manner, all individual values.

In this article, we present a new method of aggregation and its application on a multi-decision-maker problem.The multiplicity of decision-makers shows the collective importance of decision-making within organizations [5]. Indeed, each decision-maker has his or her judgment to make in relation to the action. Then, we obtain a collective classification from which a consensual result is calculated.

\section{OUTLines OF AFPC}

The AFPC (Aggregation Function Based on Pairwise Comparisons) method is based on comparisons between the performances of the alternatives on each of the considered criteria. It is astonishingly 
Joël N. Kapiamba et al.

simple but produces results as satisfactory as those produced by the highest rated aggregation functions.

\subsection{Description of the method}

The method is based on the ranking obtained by comparing the actions in pairs. An action $\mathrm{x}$ with a score greater than another action gets 2 points. There would be 0 point. In case of a tie, the two actions each 1 point.

The weights of the criteria are the geometric means of the weights assigned by the decision-makers on each criterion.

$$
\varphi\left(a_{i}\right)=\sum_{\substack{j=1 \\ j \neq i}}^{n} \sum_{k=1}^{l} g_{k} \cdot u_{i j}^{k}
$$

Where:

$g_{k}:$ Is the weight of criterion $\mathrm{k}$

$u_{i j}^{k}$ : Is the sum of the points obtained by the action $a_{i}$ with respect to the other actions $a_{j}$ for the criterion $\mathrm{k}$

$$
u_{i j}^{k}=\left\{\begin{array}{l}
2 \text { if } a_{i}^{k}>a_{j}^{k} \\
1 \text { if } a_{i}^{k}=a_{j}^{k} \\
0 \text { if } a_{i}^{k}<a_{j}^{k}
\end{array}\right.
$$

\subsection{Complexity}

$\forall k, n \in N$, for a comparison in pairs 2 to 2 on $k$ alternative and $n$ criteria, we have $\forall$ actions, $\left(\left[\frac{n \cdot(n-1)}{2}\right] * k\right)$ comparisons.

The complexity of our method is therefore $\mathcal{O}\left(n^{2}\right)$, a polynomial complexity of order 2 .

\section{DiDACTIC EXAMPLES}

\subsection{Example [6]}

A multi-criterion problem where the solution that surpasses the others must be accepted by as many people as possible, and must not be rejected too clearly, even by a single one. Each decision- maker builds the judgment matrix to retain the best product among 4 products, saying what is best compared to other products.

Table 1. Judgment Matrix for DM 1

\begin{tabular}{|c|c|c|c|c|c|}
\hline & Price & Life & Odor & Drying & Harm \\
\hline Weight & 6 & 3 & 2 & 4 & 3 \\
\hline $\mathrm{P}_{1}$ & 6 & 5 & 2 & 3 & 5 \\
\hline $\mathrm{P}_{2}$ & 5 & 6 & 3 & 6 & 4 \\
\hline $\mathrm{P}_{3}$ & 7 & 5 & 4 & 3 & 3 \\
\hline $\mathrm{P}_{4}$ & 6 & 4 & 5 & 3 \\
\hline
\end{tabular}

Table 2. Judgment Matrix for DM 2

\begin{tabular}{|c|c|c|c|c|c|}
\hline & Price & Life & Odor & Drying & Harm \\
\hline Weight & 7 & 5 & 3 & 3 & 3 \\
\hline $\mathrm{P}_{1}$ & 7 & 6 & 2 & 5 & 3 \\
\hline $\mathrm{P}_{2}$ & 6 & 5 & 2 & 6 & 4 \\
\hline $\mathrm{P}_{3}$ & 5 & 7 & 3 & 4 & 3 \\
\hline $\mathrm{P}_{4}$ & 5 & 4 & 4 & 5 & 3 \\
\hline
\end{tabular}


Table 3. Judgment Matrix for DM 3

\begin{tabular}{|c|c|c|c|c|c|}
\hline & Price & Life & Odor & Drying & Harm \\
\hline Weight & 6 & 4 & 2 & 4 & 4 \\
\hline $\mathrm{P}_{1}$ & 6 & 5 & 2 & 5 & 3 \\
\hline $\mathrm{P}_{2}$ & 7 & 6 & 3 & 3 & 5 \\
\hline $\mathrm{P}_{3}$ & 6 & 5 & 4 & 6 & 4 \\
\hline $\mathrm{P}_{4}$ & 5 & 4 & 3 & 4 & 4 \\
\hline
\end{tabular}

\section{Resolution}

The average weights for criteria are the geometric mean of the weights in relation to the following criteria:

Price $(\mathrm{C} 1) \quad: 6.3$

Life $(\mathrm{C} 2) \quad: 3.9$

Odor $(\mathrm{C} 3) \quad: 2.3$

Drying (C4) : : 3.3

Harm (C5) : : 3.3

a. Ranking matrix by actions

b. Note: Grays are the ex aequos.

Decision maker 1:

\begin{tabular}{|l|l|l|l|l|}
\hline C1 & C2 & C3 & C4 & C5 \\
\hline P3 & P2 & P4 & P3 & P4 \\
P1 & P1 & P3 & P1 & P1 \\
P4 & P3 & P2 & P2 & P2 \\
P2 & P4 & P1 & P4 & P3 \\
\hline
\end{tabular}

Decision maker 2:

\begin{tabular}{|l|l|l|l|l|}
\hline C1 & C2 & C3 & C4 & C5 \\
\hline P1 & P3 & P4 & P3 & P3 \\
P2 & P1 & P3 & P2 & P1 \\
P3 & P2 & P1 & P4 & P2 \\
P4 & P4 & P2 & P1 & P4 \\
\hline
\end{tabular}

Decision maker 3:

\begin{tabular}{|l|l|l|l|l|}
\hline C1 & C2 & C3 & C4 & C5 \\
\hline P2 & P2 & P3 & P4 & P3 \\
P1 & P1 & P2 & P2 & P1 \\
P3 & P3 & P4 & P1 & P4 \\
P4 & P4 & P1 & P3 & P2 \\
\hline
\end{tabular}

c. Analysis of criteria against Decision Maker 1

Comparison of the products against the criterion $\mathrm{C} 1$

\begin{tabular}{|c|c|c|c|c|c|}
\hline & P1 & P2 & P3 & P4 & Total \\
\hline P1 & - & 2 & 0 & 1 & 3 \\
\hline P2 & 0 & - & 0 & 0 & 0 \\
\hline P3 & 2 & 2 & - & 2 & 6 \\
\hline P4 & 1 & 2 & 0 & - & 3 \\
\hline
\end{tabular}


Joël N. Kapiamba et al.

Comparison of the products against the criterion $\mathrm{C} 2$

\begin{tabular}{|c|c|c|c|c|c|}
\hline & P1 & P2 & P3 & P4 & Total \\
\hline P1 & - & 0 & 1 & 2 & 3 \\
\hline P2 & 2 & - & 2 & 2 & 6 \\
\hline P3 & 1 & 0 & - & 2 & 3 \\
\hline P4 & 0 & 0 & 0 & - & 0 \\
\hline
\end{tabular}

Comparison of the products against the criterion $\mathrm{C} 3$

\begin{tabular}{|c|c|c|c|c|c|}
\hline & P1 & P2 & P3 & P4 & Total \\
\hline P1 & - & 0 & 0 & 0 & 0 \\
\hline P2 & 2 & - & 0 & 0 & 2 \\
\hline P3 & 2 & 2 & - & 0 & 4 \\
\hline P4 & 2 & 2 & 2 & - & 6 \\
\hline
\end{tabular}

Comparison of the products against the criterion $\mathrm{C} 4$

\begin{tabular}{|c|c|c|c|c|c|}
\hline & P1 & P2 & P3 & P4 & Total \\
\hline P1 & - & 2 & 0 & 2 & 4 \\
\hline P2 & 0 & - & 0 & 1 & 1 \\
\hline P3 & 2 & 2 & - & 2 & 6 \\
\hline P4 & 0 & 1 & 0 & - & 1 \\
\hline
\end{tabular}

Comparison of the products against the criterion $\mathrm{C} 5$

\begin{tabular}{|c|c|c|c|c|c|}
\hline & P1 & P2 & P3 & P4 & Total \\
\hline P1 & - & 2 & 2 & 0 & 4 \\
\hline P2 & 0 & - & 2 & 0 & 2 \\
\hline P3 & 0 & 0 & - & 0 & 0 \\
\hline P4 & 2 & 2 & 2 & - & 6 \\
\hline
\end{tabular}

d. Analysis of criteria against Decision Maker 2

Comparison of the products against the criterion $\mathrm{C} 1$

\begin{tabular}{|c|c|c|c|c|c|}
\hline & P1 & P2 & P3 & P4 & Total \\
\hline P1 & - & 2 & 2 & 2 & 6 \\
\hline P2 & 0 & - & 2 & 2 & 4 \\
\hline P3 & 0 & 0 & - & 1 & 1 \\
\hline P4 & 0 & 0 & 1 & - & 1 \\
\hline
\end{tabular}

Comparison of the products against the criterion $\mathrm{C} 2$

\begin{tabular}{|c|c|c|c|c|c|}
\hline & P1 & P2 & P3 & P4 & Total \\
\hline P1 & - & 2 & 0 & 2 & 4 \\
\hline P2 & 0 & - & 0 & 2 & 2 \\
\hline P3 & 2 & 2 & - & 2 & 6 \\
\hline P4 & 0 & 0 & 0 & - & 0 \\
\hline
\end{tabular}

Comparison of the products against the criterion $\mathrm{C} 3$

\begin{tabular}{|c|c|c|c|c|c|}
\hline & P1 & P2 & P3 & P4 & Total \\
\hline P1 & - & 1 & 0 & 0 & 1 \\
\hline P2 & 1 & - & 0 & 0 & 1 \\
\hline P3 & 2 & 2 & - & 0 & 4 \\
\hline P4 & 2 & 2 & 2 & - & 6 \\
\hline
\end{tabular}


Comparison of the products against the criterion $\mathrm{C} 4$

\begin{tabular}{|c|c|c|c|c|c|}
\hline & P1 & P2 & P3 & P4 & Total \\
\hline P1 & - & 0 & 0 & 0 & 0 \\
\hline P2 & 2 & - & 0 & 2 & 4 \\
\hline P3 & 2 & 2 & - & 2 & 6 \\
\hline P4 & 2 & 0 & 0 & - & 2 \\
\hline
\end{tabular}

Comparison of the products against the criterion $\mathrm{C} 5$

\begin{tabular}{|c|c|c|c|c|c|}
\hline & P1 & P2 & P3 & P4 & Total \\
\hline P1 & - & 1 & 0 & 1 & 2 \\
\hline P2 & 1 & - & 0 & 1 & 2 \\
\hline P3 & 2 & 2 & - & 2 & 6 \\
\hline P4 & 1 & 1 & 0 & - & 2 \\
\hline
\end{tabular}

e. Analysis of criteria against Decision Maker 3

Comparison of the products against the criterion $\mathrm{C} 1$

\begin{tabular}{|c|c|c|c|c|c|}
\hline & P1 & P2 & P3 & P4 & Total \\
\hline P1 & - & 0 & 1 & 2 & 3 \\
\hline P2 & 2 & - & 2 & 2 & 6 \\
\hline P3 & 1 & 0 & - & 2 & 3 \\
\hline P4 & 0 & 0 & 0 & - & 0 \\
\hline
\end{tabular}

Comparison of the products against the criterion $\mathrm{C} 2$

\begin{tabular}{|c|c|c|c|c|c|}
\hline & P1 & P2 & P3 & P4 & Total \\
\hline P1 & - & 0 & 1 & 2 & 3 \\
\hline P2 & 2 & - & 2 & 2 & 6 \\
\hline P3 & 1 & 0 & - & 2 & 3 \\
\hline P4 & 0 & 0 & 0 & - & 0 \\
\hline
\end{tabular}

Comparison of the products against the criterion $\mathrm{C} 3$

\begin{tabular}{|c|c|c|c|c|c|}
\hline & P1 & P2 & P3 & P4 & Total \\
\hline P1 & - & 0 & 0 & 0 & 0 \\
\hline P2 & 2 & - & 0 & 1 & 3 \\
\hline P3 & 2 & 2 & - & 2 & 6 \\
\hline P4 & 2 & 1 & 0 & - & 3 \\
\hline
\end{tabular}

Comparison of the products against the criterion $\mathrm{C} 4$

\begin{tabular}{|c|c|c|c|c|c|}
\hline & P1 & P2 & P3 & P4 & Total \\
\hline P1 & - & 0 & 2 & 0 & 2 \\
\hline P2 & 2 & - & 2 & 0 & 4 \\
\hline P3 & 0 & 0 & - & 0 & 0 \\
\hline P4 & 2 & 2 & 2 & - & 6 \\
\hline
\end{tabular}

Comparison of the products against the criterion $\mathrm{C} 5$

\begin{tabular}{|c|c|c|c|c|c|}
\hline & P1 & P2 & P3 & P4 & Total \\
\hline P1 & - & 2 & 0 & 1 & 3 \\
\hline P2 & 0 & - & 0 & 0 & 0 \\
\hline P3 & 2 & 2 & - & 2 & 6 \\
\hline P4 & 1 & 2 & 0 & - & 3 \\
\hline
\end{tabular}


Joël N. Kapiamba et al.

f. Matrix of scores obtained by the duels

\begin{tabular}{|c|c|c|c|c|c|c|c|}
\hline \multirow{2}{*}{ Action } & \multirow{2}{*}{ DM } & C1 & $\mathrm{C2}$ & C3 & $\mathrm{C4}$ & $\mathrm{C5}$ & TOTAL \\
\hline & & 6.3 & 3.9 & 2.3 & 3.3 & 3.3 & \\
\hline \multirow{3}{*}{$\bar{a}$} & DM 1 & 3 & 3 & 0 & 4 & 4 & \\
\hline & DM 2 & 6 & 4 & 1 & 0 & 2 & \\
\hline & DM 3 & 3 & 3 & 0 & 2 & 3 & \\
\hline \multicolumn{2}{|c|}{ Total by criterion } & 12 & 10 & 1 & 6 & 9 & 166.4 \\
\hline \multirow{2}{*}{ Action } & \multirow{2}{*}{ DM } & C1 & $\mathrm{C2}$ & $\mathrm{C3}$ & $\mathrm{C4}$ & C5 & TOTAL \\
\hline & & 6.3 & 3.9 & 2.3 & 3.3 & 3.3 & \\
\hline \multirow{3}{*}{$\tilde{a}$} & DM 1 & 0 & 6 & 2 & 1 & 2 & \\
\hline & DM 2 & 4 & 2 & 1 & 4 & 2 & \\
\hline & DM 3 & 6 & 6 & 3 & 4 & 0 & \\
\hline \multicolumn{2}{|c|}{ Total by criterion } & 10 & 14 & 6 & 9 & 4 & 174.3 \\
\hline \multirow{2}{*}{ Action } & \multirow{2}{*}{ DM } & C1 & $\mathrm{C2}$ & C3 & C4 & $\mathbf{C 5}$ & TOTAL \\
\hline & & 6.3 & 3.9 & 2.3 & 3.3 & 3.3 & \\
\hline \multirow{3}{*}{$\tilde{\Omega}$} & DM 1 & 6 & 3 & 4 & 6 & 0 & \\
\hline & DM 2 & 1 & 6 & 4 & 6 & 6 & \\
\hline & DM 3 & 3 & 3 & 6 & 0 & 6 & \\
\hline \multicolumn{2}{|c|}{ Total by criterion } & 10 & 12 & 14 & 12 & 12 & 221.2 \\
\hline \multirow{2}{*}{ Action } & \multirow{2}{*}{ DM } & C1 & $\mathrm{C2}$ & $\mathbf{C 3}$ & $\mathrm{C4}$ & C5 & TOTAL \\
\hline & & 6.3 & 3.9 & 2.3 & 3.3 & 3.3 & \\
\hline \multirow{3}{*}{ 号 } & DM 1 & 3 & 0 & 6 & 1 & 6 & \\
\hline & DM 2 & 1 & 0 & 6 & 2 & 2 & \\
\hline & DM 3 & 0 & 0 & 3 & 6 & 3 & \\
\hline \multicolumn{2}{|c|}{ Total by criterion } & 4 & $\mathbf{0}$ & 15 & 9 & 11 & 125.7 \\
\hline
\end{tabular}

g. Calculation of the coefficient of repartition

\begin{tabular}{|c|c|c|c|}
\hline & Totalbycriterion & Order of choice & Coefficient of repartition \\
\hline P1 & 166.4 & 3 & $24 \%$ \\
\hline P2 & 174.3 & 2 & $25 \%$ \\
\hline P3 & 221.2 & 1 & $32 \%$ \\
\hline P4 & 125.7 & 4 & $18 \%$ \\
\hline
\end{tabular}

The best product is product 3 (P3) for which the best total return function is 221.2.

\subsection{Example [7]}

A decision-maker group must choose a service provider from a group of partners in order to find the best of them.

The problem is to choose a partner from the following list:

$\mathrm{P} 1=$ Nippon Paint KK

$\mathrm{P} 2=$ Courtaulds Coatings Holding

$\mathrm{P} 3=$ Kansai Paint

$\mathrm{P} 4=$ International Paint

P5= US Set of Navy

The set of criterion is:

$\mathrm{C} 1=$ Product quality

$\mathrm{C} 2=$ Technology

$\mathrm{C} 3=$ Time

$\mathrm{C} 4=$ Cost

Table 1. Judgment Matrix for DM 1

\begin{tabular}{|l|c|c|c|c|}
\hline & Product Quality & Technology & Time & Cost \\
\hline Weights & 3 & 4 & 3 & 5 \\
\hline Nippon Paint KK & 6 & 8 & 9 & 4 \\
\hline Courtaulds Coatings & 4 & 5 & 6 & 7 \\
\hline International Paints & 7 & 6 & 8 & 4 \\
\hline Kansai Paint & 6 & 8 & 4 & 7 \\
\hline US Sec Of Navy & 5 & 4 & 7 & 6 \\
\hline
\end{tabular}


An Aggregation Function Based on Pairwise Comparisons

Table 2. Judgment Matrix for DM 2

\begin{tabular}{|l|c|c|c|c|}
\hline & Product Quality & Technology & Time & Cost \\
\hline Weights & 4 & 3 & 2 & 5 \\
\hline Nippon Paint KK & 7 & 5 & 3 & 8 \\
\hline Courtaulds Coatings & 3 & 6 & 8 & 4 \\
\hline International Paints & 6 & 8 & 4 & 3 \\
\hline Kansai Paint & 5 & 4 & 6 & 7 \\
\hline US Sec Of Navy & 2 & 3 & 7 & 5 \\
\hline
\end{tabular}

Table 3. Judgment Matrix for DM 3

\begin{tabular}{|l|l|l|l|l|}
\hline & Product Quality & Technology & Time & Cost \\
\hline Weights & 4 & 5 & 3 & 5 \\
\hline Nippon Paint KK & 8 & 3 & 6 & 7 \\
\hline Courtaulds Coatings & 6 & 5 & 7 & 3 \\
\hline International Paints & 5 & 8 & 4 & 2 \\
\hline Kansai Paint & 4 & 7 & 3 & 6 \\
\hline US Sec Of Navy & 7 & 6 & 5 & 8 \\
\hline
\end{tabular}

\section{Resolution}

The average weights of each criterion is the geometric mean of the weights against the criteria below:

$\mathrm{C} 1=3.6$

$\mathrm{C} 2=3.9$

$\mathrm{C} 3=2.6$

$\mathrm{C} 4=5$

a. Ranking matrix by actions

Note: Grays are the ex aequos.

Decision-maker 1:

\begin{tabular}{|l|l|l|l|}
\hline C1 & C2 & C3 & C4 \\
\hline P3 & P1 & P1 & P2 \\
P1 & P4 & P3 & P4 \\
P4 & P3 & P5 & P5 \\
P5 & P2 & P2 & P1 \\
P2 & P5 & P4 & P3 \\
\hline
\end{tabular}

Decision-maker 2:

\begin{tabular}{|l|l|l|l|}
\hline C1 & C2 & C3 & C4 \\
\hline P1 & P3 & P2 & P1 \\
P3 & P2 & P5 & P4 \\
P4 & P1 & P4 & P5 \\
P2 & P4 & P3 & P2 \\
P5 & P5 & P1 & P3 \\
\hline
\end{tabular}

Decision-maker 3 :

\begin{tabular}{|l|l|l|l|}
\hline C1 & C2 & C3 & C4 \\
\hline P1 & P3 & P2 & P5 \\
P5 & P4 & P1 & P1 \\
P2 & P5 & P5 & P4 \\
P3 & P2 & P3 & P2 \\
P4 & P1 & P4 & P3 \\
\hline
\end{tabular}


Joël N. Kapiamba et al.

b. Analysis of criteria against Decision Maker 1

Comparison of the products against the criterion $\mathrm{C} 1$

\begin{tabular}{|c|c|c|c|c|c|c|}
\hline & P1 & P2 & P3 & P4 & P5 & Total \\
\hline P1 & - & 2 & 0 & 1 & 2 & 5 \\
\hline P2 & 0 & - & 0 & 0 & 0 & 0 \\
\hline P3 & 2 & 2 & - & 2 & 2 & 8 \\
\hline P4 & 1 & 2 & 0 & - & 2 & 5 \\
\hline P5 & 0 & 2 & 0 & 0 & - & 2 \\
\hline
\end{tabular}

Comparison of the products against the criterion $\mathrm{C} 2$

\begin{tabular}{|c|c|c|c|c|c|c|}
\hline & P1 & P2 & P3 & P4 & P5 & Total \\
\hline P1 & - & 2 & 2 & 1 & 2 & 7 \\
\hline P2 & 0 & - & 0 & 0 & 2 & 2 \\
\hline P3 & 0 & 2 & - & 0 & 2 & 4 \\
\hline P4 & 1 & 2 & 2 & - & 2 & 7 \\
\hline P5 & 0 & 0 & 0 & 0 & 0 & 0 \\
\hline
\end{tabular}

Comparison of the products against the criterion $\mathrm{C} 3$

\begin{tabular}{|c|c|c|c|c|c|c|}
\hline & P1 & P2 & P3 & P4 & P5 & Total \\
\hline P1 & - & 2 & 2 & 2 & 2 & 8 \\
\hline P2 & 0 & - & 0 & 2 & 0 & 2 \\
\hline P3 & 0 & 2 & - & 2 & 2 & 6 \\
\hline P4 & 0 & 0 & 0 & - & 0 & 0 \\
\hline P5 & 0 & 2 & 0 & 2 & - & 4 \\
\hline
\end{tabular}

Comparison of the products against the criterion $\mathrm{C} 4$

c. Analysis of criteria against Decision Maker 2

\begin{tabular}{|c|c|c|c|c|c|c|}
\hline & P1 & P2 & P3 & P4 & P5 & Total \\
\hline P1 & - & 0 & 1 & 0 & 0 & 1 \\
\hline P2 & 2 & - & 2 & 1 & 2 & 7 \\
\hline P3 & 1 & 0 & - & 0 & 0 & 1 \\
\hline P4 & 2 & 1 & 2 & - & 2 & 7 \\
\hline P5 & 2 & 0 & 2 & 0 & - & 4 \\
\hline
\end{tabular}

Comparison of the products against the criterion $\mathrm{C} 1$

\begin{tabular}{|c|c|c|c|c|c|c|}
\hline & P1 & P2 & P3 & P4 & P5 & Total \\
\hline P1 & - & 2 & 2 & 2 & 2 & 8 \\
\hline P2 & 0 & - & 0 & 0 & 2 & 2 \\
\hline P3 & 0 & 2 & - & 2 & 2 & 6 \\
\hline P4 & 0 & 2 & 0 & - & 2 & 4 \\
\hline P5 & 0 & 0 & 0 & 0 & - & 0 \\
\hline
\end{tabular}

Comparison of the products against the criterion $\mathrm{C} 2$

\begin{tabular}{|c|c|c|c|c|c|c|}
\hline & P1 & P2 & P3 & P4 & P5 & Total \\
\hline P1 & - & 0 & 0 & 2 & 2 & 4 \\
\hline P2 & 2 & - & 0 & 2 & 2 & 6 \\
\hline P3 & 2 & 2 & - & 2 & 2 & 8 \\
\hline P4 & 0 & 0 & 0 & - & 2 & 2 \\
\hline P5 & 0 & 0 & 0 & 0 & 0 & 0 \\
\hline
\end{tabular}


Comparison of the products against the criterion $\mathrm{C} 3$

\begin{tabular}{|c|c|c|c|c|c|c|}
\hline & P1 & P2 & P3 & P4 & P5 & Total \\
\hline P1 & - & 0 & 0 & 0 & 0 & 0 \\
\hline P2 & 2 & - & 2 & 2 & 2 & 8 \\
\hline P3 & 2 & 0 & - & 0 & 0 & 2 \\
\hline P4 & 2 & 0 & 2 & - & 0 & 4 \\
\hline P5 & 2 & 0 & 2 & 2 & - & 6 \\
\hline
\end{tabular}

Comparison of the products against the criterion $\mathrm{C} 4$

\begin{tabular}{|c|c|c|c|c|c|c|}
\hline & P1 & P2 & P3 & P4 & P5 & Total \\
\hline P1 & - & 2 & 2 & 2 & 2 & 8 \\
\hline P2 & 0 & - & 2 & 0 & 0 & 2 \\
\hline P3 & 0 & 0 & - & 0 & 0 & 0 \\
\hline P4 & 0 & 2 & 2 & - & 2 & 6 \\
\hline P5 & 0 & 2 & 2 & 0 & - & 4 \\
\hline
\end{tabular}

d. Analysis of criteria against Decision-Maker 3

Comparison of the products against the criterion $\mathrm{C} 1$

\begin{tabular}{|c|c|c|c|c|c|c|}
\hline & P1 & P2 & P3 & P4 & P5 & Total \\
\hline P1 & - & 2 & 2 & 2 & 2 & 8 \\
\hline P2 & 0 & - & 2 & 2 & 0 & 4 \\
\hline P3 & 0 & 0 & - & 2 & 0 & 2 \\
\hline P4 & 0 & 0 & 0 & - & 0 & 0 \\
\hline P5 & 0 & 2 & 2 & 2 & - & 6 \\
\hline
\end{tabular}

Comparison of the products against the criterion $\mathrm{C} 2$

\begin{tabular}{|c|c|c|c|c|c|c|}
\hline & P1 & P2 & P3 & P4 & P5 & Total \\
\hline P1 & - & 0 & 0 & 0 & 0 & 0 \\
\hline P2 & 2 & - & 0 & 0 & 0 & 2 \\
\hline P3 & 2 & 2 & - & 2 & 2 & 8 \\
\hline P4 & 2 & 2 & 0 & - & 2 & 6 \\
\hline P5 & 2 & 2 & 0 & 0 & 0 & 4 \\
\hline
\end{tabular}

Comparison of the products against the criterion $\mathrm{C} 3$

\begin{tabular}{|c|c|c|c|c|c|c|}
\hline & P1 & P2 & P3 & P4 & P5 & Total \\
\hline P1 & - & 0 & 2 & 2 & 2 & 6 \\
\hline P2 & 2 & - & 2 & 2 & 2 & 8 \\
\hline P3 & 0 & 0 & - & 2 & 0 & 2 \\
\hline P4 & 0 & 0 & 0 & - & 0 & 0 \\
\hline P5 & 0 & 0 & 2 & 2 & - & 4 \\
\hline
\end{tabular}

Comparison of the products against the criterion $\mathrm{C} 4$

\begin{tabular}{|c|c|c|c|c|c|c|}
\hline & P1 & P2 & P3 & P4 & P5 & Total \\
\hline P1 & - & 2 & 2 & 2 & 0 & 6 \\
\hline P2 & 0 & - & 2 & 0 & 0 & 2 \\
\hline P3 & 0 & 0 & - & 0 & 0 & 0 \\
\hline P4 & 0 & 2 & 2 & - & 0 & 4 \\
\hline P5 & 2 & 2 & 2 & 2 & - & 8 \\
\hline
\end{tabular}


Joël N. Kapiamba et al.

e. Matrix of scores obtained by the duels

\begin{tabular}{|c|c|c|c|c|c|c|}
\hline \multirow{2}{*}{ Action } & \multirow{2}{*}{ DM } & C1 & $\mathrm{C2}$ & $\mathrm{C3}$ & C4 & TOTAL \\
\hline & & 3.6 & 3.9 & 2.6 & 5 & \\
\hline \multirow{3}{*}{$\frac{u}{z}$} & DM 1 & 5 & 7 & 8 & 1 & \\
\hline & DM 2 & 8 & 4 & 0 & 8 & \\
\hline & DM 3 & 8 & 0 & 6 & 6 & \\
\hline \multicolumn{2}{|c|}{ Amount by criterion } & 21 & 11 & 14 & 15 & 229.9 \\
\hline \multirow{2}{*}{ Action } & \multirow{2}{*}{ DM } & C1 & $\mathrm{C} 2$ & $\mathbf{C 3}$ & $\mathrm{C4}$ & TOTAL \\
\hline & & 3.6 & 3.9 & 2.6 & 5 & \\
\hline \multirow{3}{*}{ ن } & DM 1 & 0 & 2 & 2 & 7 & \\
\hline & DM 2 & 2 & 6 & 8 & 2 & \\
\hline & DM 3 & 4 & 2 & 8 & 2 & \\
\hline \multicolumn{2}{|c|}{ Amount by criterion } & 6 & 10 & 18 & 11 & 162.4 \\
\hline \multirow{2}{*}{ Action } & \multirow{2}{*}{ DM } & C1 & $\mathrm{C} 2$ & $\mathrm{C3}$ & $\mathrm{C4}$ & TOTAL \\
\hline & & 3.6 & 3.9 & 2.6 & 5 & \\
\hline \multirow{3}{*}{$\approx$} & DM 1 & 8 & 4 & 6 & 1 & \\
\hline & DM 2 & 6 & 8 & 2 & 0 & \\
\hline & DM 3 & 2 & 8 & 2 & 0 & \\
\hline \multicolumn{2}{|c|}{ Amount by criterion } & 16 & 20 & 10 & 1 & 166.6 \\
\hline \multirow{2}{*}{ Action } & \multirow{2}{*}{ DM } & $\mathrm{C1}$ & $\mathrm{C} 2$ & $\mathbf{C 3}$ & $\mathrm{C4}$ & TOTAL \\
\hline & & 3.6 & 3.9 & 2.6 & 5 & \\
\hline \multirow{3}{*}{$\nexists$} & DM 1 & 5 & 7 & 0 & 7 & \\
\hline & DM 2 & 4 & 2 & 4 & 6 & \\
\hline & DM 3 & 0 & 6 & 0 & 4 & \\
\hline \multicolumn{2}{|c|}{ Amount by criterion } & 9 & 15 & 4 & 17 & 186.3 \\
\hline \multirow{2}{*}{ Action } & \multirow{2}{*}{ DM } & C1 & $\mathrm{C2}$ & $\mathbf{C 3}$ & $\mathrm{C} 4$ & TOTAL \\
\hline & & 3.6 & 3.9 & 2.6 & 5 & \\
\hline \multirow{3}{*}{$\begin{array}{l}z \\
\widetilde{a} \\
\sigma\end{array}$} & DM 1 & 2 & 0 & 4 & 4 & \\
\hline & DM 2 & 0 & 0 & 6 & 4 & \\
\hline & DM 3 & 6 & 4 & 4 & 8 & \\
\hline \multicolumn{2}{|c|}{ Total by criterion } & 8 & 4 & 14 & 16 & 160.8 \\
\hline
\end{tabular}

f. Calculation of the coefficient of repartitions

\begin{tabular}{|c|c|c|c|}
\hline & Sumbycriterion & Order of choice & Coefficient of repartition \\
\hline P1 & 229.9 & 1 & $25.3 \%$ \\
\hline P2 & 162.4 & 4 & $17.9 \%$ \\
\hline P3 & 166.6 & 3 & $18.4 \%$ \\
\hline P4 & 186.3 & 2 & $20.6 \%$ \\
\hline P5 & 160.8 & 5 & $17.8 \%$ \\
\hline
\end{tabular}

The best partner is NIPPON PAINT KK for which the best return function is 229.9.

\subsection{Example}

We want to make a wise choice on three smartphones (Nokia Lumia, Samsung Galaxy S6 et Alcatel Pixi2).

This choice depends on two criteria: the price and longevity of battery (autonomy of battery). The decision maker believes that the price is more important than the longevity.

In this choice of the best phone, the price criterion at to minimize, longevity at to maximize. The information gathered on the market is as follows:

\begin{tabular}{|c|c|c|}
\cline { 2 - 3 } \multicolumn{1}{c|}{} & Price in $\$$ & Longevity in hours \\
\hline Nokia Lumia & 600 & 72 \\
\hline Samsung Galaxy S6 & 1050 & 144 \\
\hline Alcatel Pixi2 & 150 & 48 \\
\hline
\end{tabular}




\section{Example 3.a}

The Analytic Hierarchy Process method (AHP) gives the results below:

\begin{tabular}{|c|c|c|c|}
\hline & Price & Longevity & \\
\hline Weights & 0.833 & 0.167 & Value For Money(VFM) \\
\hline Nokia Lumia & 0.268 & 0.239 & 0.263 \\
\hline Samsung Galaxy S6 & 0.117 & 0.635 & 0.202 \\
\hline Alcatel Pixi2 & 0.615 & 0.136 & 0.535 \\
\hline
\end{tabular}

The last column tells us that Alcatel Pixi2 is the best alternative. By using the usual order on the real, we have the following ranking:

\section{Alcatel Pixi2 > Nokia Lumia > Samsung Galaxy S6}

\section{Example 3.b}

We will solve this example above in (3.a) by the AFPC method:

\begin{tabular}{|c|c|c|}
\cline { 2 - 3 } \multicolumn{1}{c|}{} & Price & Longevity \\
\hline Nokia Lumia & 600 & 72 \\
\hline Samsung Galaxy S6 & 1050 & 144 \\
\hline Alcatel Pixi2 & 150 & 48 \\
\hline
\end{tabular}

The set of criterion is:

- $\quad$ Price $=\mathrm{C} 1$

- $\quad$ Longevity $=\mathrm{C} 2$

We shorten the names of our different Smartphones to have a presentable table:

- $\quad$ Nokia Lumia $=$ NOK

- $\quad$ Samsung Galaxy S6=SAM

- $\quad$ Alcatel Pixi2= ALC

Weight of the criteria taking into account the scale of values on the judgment of the decision maker between price and longevity.

\begin{tabular}{|l|c|c|c|}
\hline & Price & Longevity & Geometric Average \\
\hline Price & 1 & 5 & 2.236 \\
\hline Longevity & $1 / 5$ & 1 & 0.447 \\
\hline
\end{tabular}

Comparison in pairs between smartphones in relation to price, which is a criterion to be minimized.

- $\quad$ NOK $<$ SAM score of 2 points and 0 at the opposite

- $\quad$ NOK > SAM score of 0 point and 2 at the opposite

- $\quad$ NOK $<$ SAM score of 0 point and 2 at the opposite

We can summarize the scores of our comparisons in the table below:

\begin{tabular}{|l|c|c|c|c|}
\hline & NOK & SAM & ALC & TOTAL \\
\hline NOK & - & 2 & 0 & 2 \\
\hline SAM & 0 & - & 0 & 0 \\
\hline ALC & 2 & 2 & - & 4 \\
\hline
\end{tabular}

Comparison in pairs between smartphones in relation to longevity, which is a criterion to be maximized

- $\quad$ NOK $<$ SAM score of 0 point and 2 at the opposite

- $\quad$ NOK $>$ SAM score of 2 points and 0 at the opposite

- $\quad$ NOK > SAM score of 2 points and 0 at the opposite

We can summarize the scores of our comparisons in the table below: 


\begin{tabular}{|l|l|l|l|l|}
\hline & NOK & SAM & ALC & TOTAL \\
\hline NOK & - & 0 & 2 & 2 \\
\hline SAM & 2 & - & 2 & 4 \\
\hline ALC & 0 & 0 & - & 0 \\
\hline
\end{tabular}

Matrix of scores obtained by the duals

\begin{tabular}{|c|c|c|c|c|}
\hline & Price & Longevity & & \\
\hline Weight & 2.237 & 0.447 & Score & Coefficient of repartition \\
\hline Nokia Lumia & 2 & 2 & 5.367 & $33 \%$ \\
\hline Samsung Galaxy S6 & 0 & 4 & 1.789 & $11 \%$ \\
\hline Alcatel Pixi2 & 4 & 0 & 8.944 & $56 \%$ \\
\hline
\end{tabular}

Nokia Lumia score is obtained by:

$2 * 2.37+2 * 0.447=5.367$ and so forth for the others.

We can conclude the following:

\section{Alcatel Pixi2 > Nokia Lumia > Samsung Galaxy S6}

By exploiting the Java code on an HP ProBook 4540s, the AFPC method converges more quickly in 31 Milliseconds and AHP 78 Milliseconds.

\section{Concluding Remarks}

Through Multi-Criteria Decision Aid, approaches have been developed to help groups seeking a common solution.

The aggregation function presented in this paper combines geometric mean concepts and a score on all paired comparisons. Indeed, given the non-compensatory effect of the geometric mean, it seems well indicated for this kind of problems because our method is non-compensatory.

We have come to show that with the AFPC method, we can solve a Multicriteria problem with Multi decision maker like Mono decision maker. To assess the reliability and convergence of AFPC, we have confronted it with methods such as AHP, TOPSIS and the ELECTRE series to have the same results and also confirm that AFPC converges faster than AHP and TOPSIS.

We believe that AFPC has yet to prove itself and be compared with the most common methods.

The Studenttest as the coefficient of correlation have shown that the results of our different methods are in perfect correlations.

With the data used in our study and the discrepancies between our methods and the data of our studies are random, that is, not significant.

The AFPC method remains open for a study in the direction of the fuzzy set and why not talk about fuzzy AFPC?

\section{REFERENCES}

[1]. Mousseau, V., Slowinski, R. \&Zielniewicz, P., "A user-oriented implementation of the ELECTRE-TRI method integrating preference elicitation support", Computers \& Operations Research, $27: 757$ - 777, 2000.

[2]. San Cristobal Mateo, J.R., Multi-Criteria Analysis in the Renewable Energy Industry, Green Energy and Technology, Springer-Verlag, London, 2012. DOI :10.1007/978-1-2346-0_2.

[3]. BanaEcosta, A. "Les problématiques de l'aide à la décision : Vers l'enrichissement de la trilogie choix-tri-rangement", Revue Française d'automatique, d'informatique et de recherche opérationnelle, 30(2) : 191 - 216, 1996.

[4]. Marichal, J.-M. Fonctions d'agrégation pour la décision. Brigham Young University, 2003.

[5]. Ben Khélifa, S. L'Aide Multicritère à la décision de groupe : L'approche du surclassement de synthèse. PhD Thesis, Université de Laval Québec, 1998.

[6]. RasmiGinting. Intégration du système d'aide multicritère et du système d'intelligence économique dans l'ère concurrentielle. PhD Thesis, Université de Droit et des Sciences d'AixMarseille, Janvier 2000. 
[7]. Savadogo, Z., Ngoie, R.-B. M., Ulungu, B. E.-L., Some, B. An aggregation function to solve multicriteria ranking problem involving several decision makers. International Journal of Applied Mathematical Research, 3 (4) (2014) 511-517.

\section{AUTHORS' BIOGRAPHY}

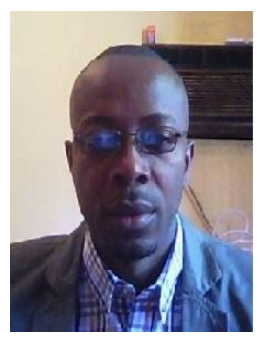

Joël Kapiamba Ntumba, is $\mathrm{PhD}$ student at university of Kinshasa. His main fields are Operations Research, Decision-making Analysis, Multi-Criteria Decisionmaking Aid, Statistics, Multi-objective Combinatorial Optimization, Computer programming, Portfolio Management Theory, and Mathematical Programming

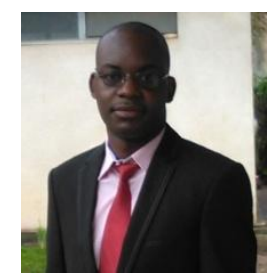

Ruffin-Benoît Ngoie Mpoy, is Professor at Institut Supérieur Pédagogique de Mbanza-Ngungu. He has obtained a $\mathrm{PhD}$ degree at Université Pédagogique Nationale (UPN), Kinshasa (DR Congo), since 2016. He teaches Algorithms Design, Computer Programming, Operations Research, Multi-Criteria Analysis, and Theory of Decision Aid at many Universities and Colleges.

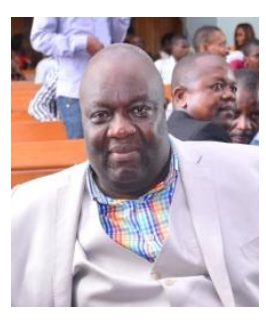

Berthold Ulungu E.-L., is Professor at Institut Supérieur des Techniques Appliquées (ISTA), Kinshasa (DR Congo). He teaches Operations Research, Graphs Theory, Applied Mathematics at many Universities and Colleges. His main fields are Mathematical Programming, Multi-Objective Combinatorial Optimization, Multicriteria Analysis, Games Theory, and Graphs Theory.

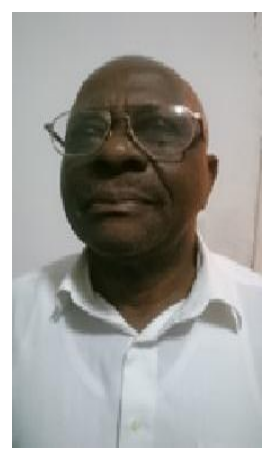

Pascal Mubenga Kampotu, is Professor at University of Kinshasa where he has taught Operations Research, General topology, and Functional analysis for forty years. $\mathrm{He}$ is a $\mathrm{PhD}$ from Western Michigan University (Kalamazoo, Michigan, USA, 1972). His works are essentially related to General Topology, Functional Analysis, optimization, Mathematical programming, and Graphs Theory. 